\title{
Renaud Bret-Vitoz, L'espace et la scène: dramaturgie de la tragédie française, 1691-1759
}

\section{Maurizio Melai}

\section{(2) OpenEdition}

1 Journals

\section{Edizione digitale}

URL: http://journals.openedition.org/studifrancesi/7919

DOI: $10.4000 /$ studifrancesi.7919

ISSN: 2421-5856

\section{Editore}

Rosenberg \& Sellier

\section{Edizione cartacea}

Data di pubblicazione: 1 juillet 2009

Paginazione: 394

ISSN: 0039-2944

\section{Notizia bibliografica digitale}

Maurizio Melai, «Renaud Bret-Vitoz, L'espace et la scène: dramaturgie de la tragédie française

1691-1759», Studi Francesi [Online], 158 (LIII | II) | 2009, online dal 30 novembre 2015, consultato il 07 janvier 2021. URL: http://journals.openedition.org/studifrancesi/7919; DOI: https://doi.org/10.4000/ studifrancesi.7919

Questo documento è stato generato automaticamente il 7 janvier 2021.

\section{(c)}

Studi Francesi è distribuita con Licenza Creative Commons Attribuzione - Non commerciale - Non opere derivate 4.0 Internazionale. 


\title{
Renaud Bret-Vitoz, L'espace et la scène: dramaturgie de la tragédie française, 1691-1759
}

\author{
Maurizio Melai
}

\section{NOTIZIA}

RENAUD BRET-VITOZ, L'espace et la scène: dramaturgie de la tragédie française, 1691-1759, Oxford, Voltaire Foundation, 2008 («SVEC 2008:11»), pp. 345.

1 Partendo dal presupposto per cui «Le lieu d'énonciation d'un discours en détermine le sens» (p. 1), Renaud Bret-Vitoz documenta l'evoluzione dello spazio scenico e la caratterizzazione progressiva del decoro tragico nel corso della prima metà del Settecento. Rientrano nel corpus preso in esame dallo studioso tutte le tragedie che abbiano riscosso un qualche successo alla Comédie-Française nel periodo compreso tra il 1691, anno che segue quello che è convenzionalmente considerato il trentennio d'oro della tragedia classica e che vede la creazione a Saint-Cyr di Athalie, ed il 1759, data della liberazione della scena dall'ingombrante presenza del pubblico. Se Athalie apre l'era dell'innovazione scenica attraverso un finale fondato sulla rottura dell'unità di luogo e sull'effetto spettacolare di un decoro mobile, la scomparsa delle «banquettes» dalla scena pone fine al periodo fecondo in cui l'aspirazione alla libertà stimola l'ingegno degli autori tragici, costretti ad ideare ogni forma di escamotage e di soluzione sperimentale al fine di aggirare l'ostacolo materiale della ristrettezza spaziale. Segnato da tentativi individuali e frammentari, ricco di ricerche e di sperimentazioni ma povero di risultati effettivi o di grandi nomi che si siano imposti alla posterità, il periodo in questione, definito da Focillon come l' «âge du raffinement» della tragedia, è senz'altro da ricordarsi per la conquista di un «lieu d'action pittoresque et signifiant, qui n'est ni le lieu indifférencié de la tragédie classique ni le tableau envahissant du drame romantique» (p. 1). Contrapponendo i concetti di «espace dramatique», inteso come dimensione spaziale astratta, puramente mentale, evocata solo attraverso gli strumenti 
retorici, e di «lieu scénique», inteso come scena concreta e visibile dallo spettatore, Bret-Vitoz mostra la progressiva intrusione del secondo nel primo, ovvero l'importanza crescente assunta da elementi concreti quali lo scenario, il costume, l'effetto scenico ed il «jeu dramatique» nel passaggio dalla tragedia classica alla tragedia post-classica. Il gusto di un pubblico sempre più allargato e socialmente composito impone ai tragediografi di nuova generazione una trasposizione del dicibile in visibile, della narrazione in azione, del testo in spettacolo. Valorizzare la scena in quanto «lieu scénique» concreto significa aprire lo spazio tradizionalmente immateriale ed atemporale della tragedia alla dimensione storica: che concerna il territorio nazionale o le terre più remote ed esotiche, la storia invade la scena tragica portandovi le più svariate civiltà con i loro usi e costumi, descritti con profusione di dettagli pittoreschi e di «couleur locale». Allo stesso tempo, il decentramento del luogo dell'azione dall'indeterminato ed isolato «palais à volontà» classico verso spazi aperti quali la piazza pubblica o il senato o verso spazi intimi e borghesi quali le abitazioni di privati riflette l'epocale trasferimento del nucleo della vita politica francese dalla «Cour» alla «Ville» e l'affermarsi di un nuovo tipo di società, in cui il cittadino non è più spettatore distante dei luoghi segreti ed inarrivabili del potere assoluto, ma agente attivo della storia in divenire. La sperimentazione scenica trasforma il quadro dell'azione in un vero e proprio paesaggio, tridimensionale, composito ed architetturalmente strutturato, in cui si moltiplicano gli antri percorribili ed i nascondigli praticabili che, frazionando lo spazio tragico, minano dall'interno il principio dell'unità di luogo. Caso esemplare di tentativo di aggiramento della regola dell'unità di luogo è la rappresentazione di Sémiramis del 1748, per la quale Voltaire giunge ad ispirarsi al principio pitturale della conversione del tempo in spazio, ripartendo la scena in tre settori distinti e giustapposti. Sono del resto numerosi gli spunti che la pittura offre agli innovatori della scena tragica: l'estetica del «tableau», imponendosi gradualmente a scapito della pratica classica del «récit», si insinua all'interno del genere tragico prima ancora di essere teorizzata da Diderot per il dramma borghese. Lo studio di BretVitoz, oltre a documentare ampiamente gli sviluppi della riflessione teorica e della pratica teatrale che determinano il passaggio della tragedia francese da arte retorica ad arte dello spettacolo, ha il merito di soffermarsi sulle contraddizioni ed i nodi irrisolti che si delineano come la fisiologica contropartita alle conquiste dei tragediografi postclassici: la concorrenza che viene a crearsi tra i due poli ormai difficilmente conciliabili della narrazione e dell'azione, della parola e dell'immagine, genera un'inevitabile quanto irreparabile tensione, che mette in causa non solo la questione della rappresentazione dello spazio scenico ma l'intero impianto strutturale del genere tragico. 